\title{
El giro a la izquierda y la confianza en el Estado. El proceso ecuatoriano
}

\author{
Diana Plaza Martín*
}

Perfiles Latinoamericanos, 24(48)

2016 | pp. 7-32

DOI: $10.18504 / \mathrm{pl} 2448-001-2016$

\begin{abstract}
Resumen
Los liderazgos políticos de izquierda que emergieron en América Latina al iniciar el siglo xxı para responder a las crisis de las dos últimas décadas del siglo xx, tuvieron en común que buscaron devolver la confianza en las instituciones. Consignas tales como “¿Que se vayan todos!” responsabilizaban en particular a la clase política y abrían el escenario a novedosos proyectos. Esta novedad estaría en el contenido de las propuestas y en la estrategia para llegar al poder. Ante el conflicto de representación que vivían países como Ecuador, se optó por un peligroso movimiento que se reveló primero como una crisis de las instituciones, para después proponer el discurso de "volver a tener patria". Un ejercicio que ha mantenido en el poder a la mayoría de los que "giraron a la izquierda", tras varias victorias electorales contundentes.
\end{abstract}

\begin{abstract}
The leftist political leaderships emerged at the beginning of the 21 st century as a response to the crisis occurred during the last two decades of the 20th century in Latin America, shared the necessity of recovering the confidence in institutions. Slogans such as "Throw them all out!" pointed at the ruling political class as the main responsible for the situation and opened the political arena to new projects. This "newness" had to do not only with the content of the political proposals, but also with the strategy to attain power. Given the crisis of representation experienced in countries like Ecuador, it was made a dangerous choice. It was firstly deepen the institutional crisis, to subsequently propose a new closure of meaning through a political discourse dominated by the need to "regain the fatherland". A great majority of those who "turned left" and resorted to this political strategy are still in power after several and overwhelming electoral victories.
\end{abstract}

Palabras clave: giro a la izquierda, Rafael Correa, Ecuador, América Latina, crisis. Keywords: Left turn, Rafael Correa, equateur, Latin America, crisis.

* Doctoranda en Ciencia Política, especialidad en Estudios Contemporáneos de América Latina por la Universidad Complutense de Madrid. Docente en la Universidad Iberoamericana, Ciudad de México. 


\section{Introducción}

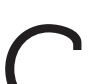
merías del siglo xx con una crisis económica, ${ }^{1}$ política, ${ }^{2}$ social ${ }^{3}$ y de representación. Las tres primeras son más fáciles de analizar, puesto que son mensurables en mayor o menor grado, ${ }^{4}$ pero la cuarta, más abstracta, es la que propiciará que aquellas tres devengan en una crisis estructural generalizada ${ }^{5}$ como la que vivirá Ecuador al iniciar el siglo xxI.

1 Entenderemos aquí crisis económica desde su definición ortodoxa, esto es, como la fase más profunda de un ciclo recesivo en el que junto a la caída del PIB (en 1999 el PIB ecuatoriano cayó a -6.3\%, para recuperarse a valores de inicios de los noventa en 2002 y bajar de nuevo en 2004) se destruye el empleo, lo que, a su vez, reduce el consumo. Sin embargo, la de Ecuador, en específico, se considera "crisis financiera", refiriéndose a que su origen no se dio en la economía real del país, sino en problemas del sistema financiero o monetario. Es importante señalar que hay tres tipos de crisis financieras: 1) cambiarias: cuando un movimiento especulativo contra una moneda se traduce en devaluación; 2) bancarias: cuando la quiebra o los retiros masivos (reales o potenciales) de depósitos inducen a los bancos a suspender la convertibilidad interna de sus pasivos, $\mathrm{u}$ obligan a las autoridades a intervenirlos o asistirlos para impedir las quiebras y/o los retiros de depósitos; 3) deuda externa: cuando no se puede atender el pago de la deuda contraída en el exterior, ya sea soberana o privada. Las tres modalidades se presentaron en Ecuador, provocando pauperización, aumento de la desigualdad, y la mayor migración de ecuatorianos, lo que agudizó la crisis social debido a la desestructuración de los hogares. Para profundizar en el fenómeno migratorio vinculado a la crisis económica véase Ramírez J. P. \& F. (2005).

2 Por crisis política entenderemos la desestabilización del orden institucional que en Ecuador se evidenció con el forzado acortamiento de tres gobiernos: Abdalá Bucaram (destituido por incapacidad mental), Jamil Mahuad y Lucio Gutiérrez (quienes renunciaron tras fuertes protestas ciudadanas).

Por crisis social entenderemos la manifestación del malestar ciudadano por medio de movimientos sociales y sus protestas, para Ecuador en particular el Movimiento Indígena y la Insurrección de Abril. En este concepto de crisis social incluiremos al aumento de la violencia vinculada a la cultura y contexto de pobreza, producto de las crisis económicas y políticas del periodo, que todavía representa uno de los principales problemas del país al unísono de la desigualdad.

4 Si bien para todas estas crisis se pueden utilizar cifras, cabe matizar que uno de sus componentes más importantes es la incertidumbre, por esta causa no todo en ellas es mensurable.

5 En términos gramscianos sería una crisis orgánica. Es decir, la agudización de una crisis estructural en la que se favorezca la aparición de un bloque histórico nuevo como consecuencia de la crisis de la hegemonía o ruptura de los lazos entre la estructura y la superestructura. La crisis orgánica es concebida por Gramsci como una disgregación del bloque histórico, en el sentido de que los intelectuales encargados de hacer funcionar el nexo estructura-superestructura, se separan de la clase a la que estaban orgánicamente unidos y no permiten que ejerza ya su función hegemónica sobre el conjunto de la sociedad: "La clase dominante ha perdido el consenso." Esto es, que ya no es dirigente sino solo dominante, detentadora de una fuerza coercitiva pura. La crisis orgánica de una clase o grupo sobreviene cuando estos han desarrollado todas las formas de vida implícitas en sus relaciones sociales, pero, gracias a la sociedad política y a sus modos de coerción, la clase dominante se mantiene artificialmente como tal e impide su remplazo. Una crisis orgánica puede deberse al fracaso de una empresa política de la clase dirigente, que impone por la fuerza el consenso social. (Gramsci cita el ejemplo de la crisis orgánica originada por la Gran Guerra.) O bien, puede originarse en las grandes masas de la población que pasan súbitamente de la inactividad política a una cierta actividad y plantean reivindicacio- 
En este sentido, la crisis de representación se define aquí como aquella que es posible medir en la percepción de ilegitimidad que surge entre la ciudadanía frente al orden institucional imperante, al señalarlo como incompetente o como culpable principal de la situación. Es un tipo de crisis que tiene su mejor escenificación en el grito “iQue se vayan todos!”, nacido en diciembre de 2001 en Argentina tras el decreto del corralito, pero extendido después en gran parte de los países del Cono Sur, incluido Ecuador.

Partiendo de esta ilegitimidad, el arribo a la crisis estructural generalizada (CEG) supondrá otra vuelta de tuerca, ya que para salir no valdrá la mera propuesta de reformas, sino que demandará un cambio también estructural o de paradigma, funcione o no, se cumpla o no, ${ }^{6}$ lo que en nuestra terminología denominaremos "contorno social".

La respuesta a esa crisis (y novedoso cierre de sentido) es la que a nuestro juicio dará el discurso de Rafael Correa $(\mathrm{RC})$ desde su postulación, en septiembre de 2005, para asumir el Ejecutivo; y es con la que finalmente llega al poder en noviembre de 2006 tras su victoria electoral en la segunda vuelta.

Para acometer la explicación del mencionado fenómeno, daremos, en primer lugar, una mayor definición metodológica, en particular de la crisis estructural generalizada y su análisis discursivo aplicado al caso ecuatoriano. Luego se expondrán concisamente las características de Ecuador, entre finales del siglo xx y principios del xxI, haciendo hincapié en las fracturas internas, étnicas y regionales, y en la implicación de las políticas neoliberales en las crisis ya citadas, como antesala al contexto de la CEG acaecida en 2005 y, particularmente, durante la "revuelta forajida". Por último, se discutirá la propuesta de Rafael Correa a esas crisis analizando dos textos claves por su representatividad en relación con la recomposición interna y externa en el momento post CEG, a saber: su discurso de investidura de enero de 2007, como culminación de la campaña electoral, y

nes que en su propio complejo inorgánico constituyen una revolución. La crisis orgánica que consiste en la desaparición del consenso que las clases subalternas acuerdan con la ideología dominante, no puede culminar con la aparición de un nuevo bloque histórico, lo que solo sucede cuando la clase dominada, fundamentalmente, sabe construir, por la mediación orgánica de sus intelectuales, un nuevo sistema hegemónico dominante capaz de oponerse al anterior y ser eficaz para extenderse a todo el ámbito social. Es decir, capaz de conquistar a la sociedad civil como preludio de la conquista de la sociedad política. En este sentido, el concepto manejado por este trabajo es deudor en cadena del trabajo gramsciano, ya que además de este concepto, utiliza la teoría laclauniana sobre la construcción de hegemonía, la que a su vez bebe de la gramsciana. Así, en el concepto de crisis estructural generalizada estarían presentes la herencia gramsciana sobre una situación en la que "lo viejo no muere y lo nuevo no puede todavía nacer”, y la teoría laclauniana sobre la construcción de hegemonía basada en la necesidad de la existencia de lógicas en tensión: equivalencia y diferencia y la construcción discursiva de la realidad mediante el concepto lacaniano de significante.

6 La salida no tiene que ser propuesta en términos de "progreso", también puede ser una propuesta de corte autoritario. 
el Plan de Gobierno Plurianual 2007-2011, en tanto versión amplia y discernida de todo lo recogido como demandas sociales durante la campańa electoral y las respuestas pretendidas para ellas.

\section{Sobre las crisis estructurales generalizadas y su manifestación ecuatoriana}

"La hora más obscura es la más próxima a la aurora."

Eloy Alfaro

En este punto seguiremos a Alba (2003), quien entiende que una CEG es aquella que se caracteriza por la desestructuración de las estructuras, más que por la estructuración de nuevas estructuras. Las crisis arriba señaladas pertenecen al reciente escenario de cambio de siglo dominado por la ausencia de horizontes utópicos y, por consiguiente, de proyectos políticos y sociales (Alba, 2003: pp. 50-51). Así, estaríamos ante un proyecto neoliberal totalitario, puesto que abarca lo económico, lo político y lo social, y del cual parece imposible salir. La única zona de maniobra pareciera estar entre la gestión de una economía más social, versión del Welfare State europeo, y otra más puramente neoliberal como el modelo estadounidense.

Ante este camino sin salida, continúa Alba, es fácil encontrar posiciones de desesperanza, pesimistas y catastróficas respecto al presente y el futuro. Pero también posturas que tomen a esa situación como un "crisol de oportunidades inéditas para contribuir de diversas formas a la tarea de transformar la realidad" (Alba, 2003: p. 52). Si bien una CEG es propicia para rendirse ante la adversidad, también lo es para plantear propuestas de cambio radical. En esto último situamos aquí el discurso de RC, al considerar que algunos de sus componentes como la expropiación petrolera, la revocación del TLC o la suspensión de pagos de la deuda externa, ${ }^{7}$ difícilmente se habrían puesto sobre la mesa por parte de una candidatura política en otro momento de menor apertura al cambio.

La coyuntura en la que RC aparece es una de las claves del éxito en la construcción de una propuesta política hegemónica en términos gramsciano-laclau-

7 Las deudas contraídas por Ecuador en los noventa fueron declaradas por el gobierno desde el concepto jurídico del derecho internacional como "odiosas o ilegítimas", es decir, creadas y utilizadas contra los intereses ciudadanos y, por ello, susceptibles de ser anuladas como se haría con un contrato obtenido por coacción. Este proceso lo inició RC en 2005 cuando era titular de la cartera de Economía, y finalizado en 2008 bajo su presidencia. 
nianos. Una propuesta que además de buscar el poder, quiso hacerlo de forma hegemónica consiguiendo el más amplio consenso social; lo que en nuestro entramado teórico correspondería a articular las demandas particulares excluidas del sistema en una cadena equivalencial, ${ }^{8}$ en pos de generar un núcleo común: el cambio estructural del sistema político-económico. En este ejercicio de articulación, las demandas deberán vaciarse de una parte de su particularidad para emprender la construcción de un universal (RC: Revolución CiudadanaRafael Correa) con el cual identificarse y luchar por la hegemonía en el campo político ecuatoriano. Esta construcción del universal en la lucha política tradicionalmente la encarna un liderazgo personal (RC) y/o, aunque en menor grado, organizacional (Alianza PAIs).

Así mismo, consideramos que las características contempladas por Alba (2003: p. 51) en una situación de CEG, tienen lugar en Ecuador entre 1998 y 2006 de la siguiente forma:

1. Hay una desestructuración de estructuras interrelacionadas que forman una estructura mayor como el Estado-nación. En este artículo se retoman los indicativos que componen las crisis de las estructuras económica, política, social y de representación como muestra de la crisis de las estructuras interrelacionadas del Estado-nación, lo que también justificará que la situación ecuatoriana de ese momento aquí se le considere como una CEG.

2. Amplitud de tiempo: se producen durante un largo periodo y por esto es imposible predecir su fin. Sobre este aspecto, se considerará como inicio de la CEG ecuatoriana el año 1998 (una duración de ocho años), esto con base en los eventos que desatan las crisis ya citadas en los pies de página 1,2 y 3 . Tocante a la dificultad de predicción, el que el inicio del fin se diera en una insurrección ciudadana espontánea, en un acontecimiento, ${ }^{9}$ lo ejemplifica.

8 Se retoma el concepto de cadena de equivalencias acuńado por Laclau para referirse al proceso de formación de un significante vacío o flotante mediante la articulación de demandas no absorbidas por el sistema, que durante la formación de una identidad política se vaciarán de parte de su particularidad para conformar un universal que las represente.

9 Badiou (1988) acuña el concepto de acontecimiento y su importancia en un contexto donde el paradigma neoliberal es hegemónico. Para Badiou, el acontecimiento es el acto que subvierte la hegemonía o sistema de creencias de tal forma que el vacío primordial de la condición humana se devela. Quedan a la vista la falta de metas u objetivos, pero la posibilidad de cambio, la abertura. En el presente artículo, la Revolución de Abril es el acontecimiento que revela el fracaso del sistema hegemónico neoliberal en Ecuador y abre la posibilidad de reformularlo, para construir un nuevo orden hegemónico como el que instalará RC. No obstante, el acontecimiento no es parte necesaria de la CEG. 
3. La desestructuración de las estructuras se produce en diferentes momentos, espacios y maneras. Esto es, que no son consecuencias de un mismo fenómeno, sino que sus causas son múltiples y variadas, y en la mayoría de los casos estos se encuentran interrelacionados al igual que las estructuras. En este sentido, es obvio que la crisis económica ecuatoriana se vinculaba a las decisiones de la clase política y que ambas causaban el malestar detonante de las protestas sociales. Eran diferentes causas, pero todas se interrelacionaban.

4. Oportunidad de cambio: posibilitan la constitución de nuevas estructuras al desestructurar las existentes, por lo que es importante enfrentarlas de forma creativa y comprometida, ya que de no proponer algo "nuevo" la crisis se mantendrá por un tiempo indeterminado. Ejercicio que, a nuestro juicio, realiza discursivamente $\mathrm{RC}$ y por el que a pesar de las grandes dificultades (en particular la fuerte deslegitimación de la clase política y las instituciones) consigue llegar al poder.

\section{La CEG y su manifestación discursiva}

La CEG se caracteriza discursivamente ${ }^{10}$ por una ruptura de las cadenas equivalenciales y porque esto provoca la proliferación de significantes flotantes. ${ }^{11} \mathrm{Es}$ decir, que abre un espacio donde la posibilidad de resignificar algunos significantes flotantes o Amo como "Ecuador", "Nación", "Estado", etc., no solo son posibles sino necesarios, ya que el significante Amo que fungía como anclaje de la cadena significante que aglutinaba a la masa (ecuatoriana), en esta nueva circunstancia, ha dejado de funcionar (crisis de representación).

Este contexto de aparición de significantes flotantes no articulados (elementos) es descrito en términos de oportunidad política por Barrera (2008: p. 122) para explicar el triunfo de Alianza País en la elección de la Asamblea Consti-

10 En este artículo, el concepto de discurso toma lo social como una construcción simbólica y en sentido amplio: productor de sentido o, en palabras de Derrida, el "pensamiento" (discurso escrito u oral) como "acto". Un acto que no tiene por qué ser eficaz en la acepción clásica de producir efectos concretos materiales: "si yo quiero mover una silla pienso: pensar en ella no basta, eso recibe el nombre de animismo", pero que es un acto eficaz porque ayuda a crear aquello que nombra, y esto sucede en toda acción ya sea científica, política o técnica (Derrida, 1994). [Ref. 1 septiembre de 2012].

11 El significante flotante es para Laclau (2005) el equivalente o una deriva del significante Amo lacaniano, también conocido como "point de capiton" (punto de capitonaje), denominación literal del lugar en el que la aguja entra y sale en la costura, es decir, donde el hilo se anuda para continuar cosiendo. Estos puntos son los significantes que irradian y organizan el sentido para el sujeto. Gracias a dichos puntos de convergencia que fijan momentáneamente la cadena significante el sujeto encuentra, retrospectiva y prospectivamente, referencias dentro de la masa flotante de las significaciones. 
tuyente cuando reconoce que "si bien ha influido tener un 'buen candidato', es sin duda también producto de un momento fluido de la historia, donde las formas de dominación y las propias instituciones y actores de esta dominación se están desvaneciendo". A lo que añadió una frase clave para este artículo: "la significación más alta del proceso es que comienza el fin de la larga noche neoliberal." Esto es, que en la "desestructuración de las estructuras", en la caída del sistema de significación dominante, se encuentra la abertura que permite la construcción de un nuevo orden, por encima del "buen candidato" y sus propuestas, ya que estas son derivadas o consecuentes de una CEG.

Así es como RC se dará a la tarea de resignificar ciertos significantes flotantes, en particular los de "Ecuador/Nación"12 y "Estado", para lo cual el propio Correa fungirá como líder y significante Amo que articule la cadena equivalencial y fije el exterior constitutivo, ${ }^{13}$ mediante el que se genera una comunión de subjetividades en torno a Ecuador y a los tradicionales representantes de los ecuatorianos (Estado).

\section{Ecuador entre finales del siglo XX e inicios del XXI: fracturas internas y externas}

La desestructuración a la que Ecuador se aboca en 2005 proviene de siete años en los que la norma fue la inestabilidad política, el continuo deterioro de los indicadores económicos y sociales, y las protestas ciudadanas, en particular las del movimiento indígena, que en múltiples ocasiones habían roto la "calmada" marcha del país. La incertidumbre, la conflictividad y el deterioro del nivel de vida de una gran parte de la población marcaban la agenda.

12 En este trabajo no se pretende problematizar el concepto de Estado-nación, pero conviene anotar que en tanto que los Estados-nación mantienen su vigencia como forma de organización política, es necesario que, para evitar una crisis de gran magnitud, el Estado tenga legitimidad si pretende gobernar la nación. De este modo, el proceso de construcción y reproducción del cemento ideológico de la comunidad política Estado-nación, aún es una tarea a la que los designados como representantes de los ciudadanos se deben abocar si desean una adecuada gobernabilidad.

13 Según Laclau (2005), se requiere siempre de una lógica de la equivalencia con la cual se forme el significante vacío o flotante. En dicha lógica se pierde la particularidad en pos de la generalidad, pero con ella se mantiene un cordón umbilical con la lógica de la diferencia; en esta última se afirma la particularidad con lo que se construye la frontera que deja fuera el exterior constitutivo. Con esto se afirma que todo grupo o masa se constituye dejando fuera de su estructura al menos un elemento. Lo que se deja fuera de toda colectividad son las subjetividades que no comparten las mismas coordenadas territoriales, y las que comprenden distinto el referente común que conglomera a la colectividad (Plaza, 2010: pp. 7-8). Estas externalidades rebosarán el discurso de RC, debido a que su primer paso fue insistir en la ruptura.

D. Plaza Martín | El giro a la izquierda y la confianza en el Estado. El proceso ecuatoriano Perfiles Latinoamericanos, 24(48) | FLACso México | pp. 7-32 | DoI: 10.18504/pl2448-001-2016 
Es un periodo que RC llamó la "larga noche neoliberal" y "el neoliberalismo o el no país: 1990 hasta el presente". ${ }^{14}$ Fueron años en los que bajo la consigna de la "eterna" necesaria modernización del país, se emprendieron las reformas neoliberales signadas por el Consenso de Washington, cuyo principal objetivo era el pago de la deuda externa vía el recorte de los gastos del Estado. Los efectos de esas políticas son conocidos y estas, unidas a la altísima corrupción política, provocaron que en 2005 estallara en Ecuador la denominada peyorativamente "revuelta forajida" y positivamente "revolución de Abril".

No obstante, las fracturas históricas del país, la étnica y la regional, tampoco se atenuaban, a pesar de que en la Constitución de 1998 se reconocía la pluriculturalidad y multietnicidad, y de que se había incluido lo indígena en la vida política ecuatoriana con la llegada al poder, en 2003, de Lucio Gutiérrez en alianza con el movimiento indígena Pachakutik, fundamental para su éxito. Mientras que el tema de la población afroecuatoriana, que algunos consideraban como "el otro del otro" o el "último Otro", ni siquiera había entrado al debate. ${ }^{15}$

En lo regional, la mencionada fractura está tan naturalizada en la vida política de Ecuador, que no se observa como un obstáculo para la buena marcha del país. O, más bien, es complicado — por no decir imposible— que algún partido o líder políticos se presente como "nacional", ya que esto suele leerse no como beneficio para el país, sino como negación de los intereses de los pueblos de la "Costa" o de la "Sierra"16 (Alcántara, 2001: p. 129). Es así como el regionalismo partidario "se manifiesta esencialmente en la dificultad para gobernar el sistema político puesto que las tendencias identificadas conducen a la fragmentación y al conflicto" (Alcántara, 2001: p. 150). Lo que en nuestro caso de estudio se evidencia con el enfrentamiento de la segunda vuelta donde el empresario bananero Noboa representaba los intereses de la Costa, de Guayaquil, en oposición a RC que representaba a los de la Sierra para una buena parte de la población. No obstante, la histórica polaridad regional será

14 En Correa (2004), se describe la economía ecuatoriana (a comienzos de los setenta inició la explotación del petróleo, lo que transformó al país y puso fin al modelo primario-exportador) de las tres últimas décadas del siglo xx en tres periodos: el boom petrolero (1972-1981), la crisis de la deuda (1981-1990), y el periodo del Consenso de Washington (1990 hasta el presente).

15 Para profundizar en la representación negativa (violencia, enfermedades, etc.) de la población ecuatoriana afrodescendiente véase Muteba (1999). Y para acercarse a su invisibilidad social y política a Walsh \& García (2002).

16 Para el campo político ecuatoriano esto es vital, ya que tradicionalmente la lucha electoral se había dado desde el regionalismo, es decir, gobernar la nación desde la Costa o la Sierra (con un presidente de un lado y un vicepresidente del otro, en ocasiones). En este sentido, Correa señalaba una diferente partición del espacio político pues propuso: "construir un proyecto hegemónico: inclusivo y claro. Un consenso con todos los sectores que quieren el cambio. Construir una utopía realista: no un partido para ganar elecciones, sino un 'contingente político para transformar el país', la gran mayoría del país" (Barrera, 2008: p. 124). 
bien salvada por RC al posicionar a Noboa como "vendedor de la patria", es decir, al situar el enfrentamiento más allá del terreno regional, para colocarlo en el (económico)-nacional. Justo donde el economista-nacional RC nacido en Guayaquil tenía más oportunidades de ganar, como finalmente se evidenció.

En resumen, el periodo neoliberal no redujo las tensiones/fracturas étnicas y regionales e incluso las acució con la ingente corrupción política, el deterioro de las condiciones de vida de la población y la invisibilización de las mismas, con base en un programa de reestructuración que supuestamente traería la ansiada "modernidad" europea, estadounidense, etc. al Ecuador y donde los "viejos" problemas no tienen lugar.

En este contexto de crisis tendrá lugar la "revuelta forajida".

\section{La revuelta forajida como manifestación extrema de la CEG}

La "revuelta forajida" ocurrió entre el 13 y el 20 de abril de 2005. Toma su nombre del calificativo que Lucio Gutiérrez, el presidente de Ecuador en aquel momento, utilizó para denominar a los ciudadanos que la noche del día 14 protestaron frente a su domicilio particular. Desde ese instante ser un "forajido" significaba estar a favor de la salida de Gutiérrez y de la revocación del Congreso y, en general, estar en contra de todas las instituciones que tradicionalmente representan al pueblo, entre otras, los partidos políticos.

Es aquí cuando la "partidocracia", como después RC denominará a la tradicional clase política ecuatoriana, se convertirá en la enemiga de Ecuador. Es por esto que RC se postulará al Ejecutivo como un outsider, sin ningún partido que lo respaldara directamente en el Legislativo. ${ }^{17}$ Esta maniobra —a priori muy peligrosa, ya que no tener apoyos explícitos en el Congreso dificulta la tarea ejecutiva- será uno de los principales motivos por los que RC llega el poder. Pero no se debe perder de vista que esa maniobra va de la mano de una de sus propuestas de campaña más importantes: una consulta ciudadana que convocaría a una Asamblea Constitucional para reformar estructuralmente al país. Así, $\mathrm{RC}$ se presenta por fuera de la "partidocracia" y como propuesta de una reforma estructural del sistema. Ambos, reclamos centrales de la "revuelta forajida".

17 Alianza pAIS se funda a inicios de 2006 para servir de plataforma política a RC, pero no presentó candidatos para el Congreso. No obstante, firmó una alianza política con el Partido Socialista-Frente Amplio que llevó candidatos para el Congreso nacional, y el 31 de julio de 2006 firmó un Acuerdo Político Programático con el Partido Comunista del Ecuador cuando Correa se postulaba para candidato presidencial. Ya en la segunda vuelta se unieron a Alianza PAIs partidos como Movimiento Popular Democrático, Izquierda Democrática, Pachakutik y Partido Roldosista Ecuatoriano. 
Cabe remarcar que la "revuelta forajida" detentaba un fuerte sentimiento de traición —ilegitimidad hacia aquellos con cargos de representación-, pero no era antiinstitucional. Asimismo, durante la protesta se combatió con fervor a todos los que quisieron encabezar la movilización —incluidos los líderes de las organizaciones de izquierda y los del movimiento indígena— ${ }^{18}$ y se exigía “ $\mathrm{QQue}$ se vayan todos!", mas no se pedía que las instituciones democráticas quedaran vacías o se construyera otro sistema de gobierno. Entonces no había liderazgo político que se fuera a aceptar, pero, al mismo tiempo, se reclamaba uno que asumiera su protesta. Esta asunción la enarbolaría casi de inmediato RC con su salida del gobierno interino de Alfredo Palacio al comprobar que este no tenía la menor intención de debatir abiertamente la "agenda de Abril". ${ }^{19}$

Tal escenario se describe en la obra colectiva La revolución de Abril no fue solo una fiesta a manera de "antinomia, 'sociedad vs. Políticos", exigiendo la revocación del Congreso con la misma fuerza que se clamaba la de Gutiérrez. Así mismo, "las representaciones sociales también fueron puestas bajo cuestión. Ningún tipo de liderazgo fue admitido ni será tolerado. La misma idea de representación no tuvo asidero en un discurso en el que la utopía de la autogestión societal se coloca en el centro de una refundación justa de la República sin partidos" (Ramírez, 2005: p. 71).

Y aunque es posible afirmar que "la insurrección de Abril se hizo sin vanguardia ni bandera” (Ramírez, 2005: p. 73) conocida, sí existía un punto de capitón o significante Amo que los unía: el malestar con las instituciones de representación. El “¿Que se vayan todos!” era el significante Amo que recogía las diferentes demandas de la sociedad, y que contenía un núcleo común que posibilitaba su aglutinamiento. Significante Amo de carácter estructural, es decir, con una alta carga universal-común, propia de una CEG. $^{20}$

18 A diferencia de los derrocamientos de Bucaram (1997) y de Mahaud (2000) cuando el liderazgo político de la protesta social estaba en manos de instituciones (organizaciones del MIE y de la Coordinadora de Movimientos Sociales), en 2005 no existía ninguna dirección política organizada (Ramírez, 2005: pp. 23-24).

19 En ese momento RC fungía como ministro de Hacienda de Alfredo Palacios, cargo desde donde defendió que el $80 \%$ de los ingresos petroleros debían destinarse al país, y el 20\% al pago de la deuda externa. A ello respondió el Banco Mundial amenazando con cerrar los préstamos al país, posición por la que RC dimitió alegando que no se plegaría a los intereses y amenazas del Banco Mundial. RC adquirió entonces la denominación de "ministro forajido" y comienza la elaboración de su discurso político absorbiendo las demandas repelidas por el sistema, como las recogidas en la "agenda de abril".

20 Las reivindicaciones no eran "concretas", relacionadas con las políticas económicas en específico, sino de orden más estructural: sobre la ética de la clase dirigente: justicia, impunidad, traición y agravio hacia la ciudadanía (Ramírez, 2005: p. 76). En este reclamo quedaban implícitas las medidas económicas concretas tomadas por ellos, las cuales se consideraban injustas e ilegítimas. Esto, más adelante, daría la pauta a RC de declarar como ilegítima una parte de la deuda soberana. 
Con esa base es posible definir a la insurrección de abril como institucional y refundacional, puesto que se pedía que las instituciones democráticas y de representación del pueblo fueran refundadas no destruidas. Es una refundación necesaria tras un escenario de desestructuración como el arriba descrito y que RC intensificará para que su lema "Para volver a tener Patria" tenga el éxito suficiente para que él alcanzara el poder.

No obstante, la insurrección de abril tuvo en su carácter marcadamente regional un componente "negativo" para la refundación del país que RC proponía; esto será más notable cuando Gutiérrez atrajo población de otras provincias, misma que fue repelida por los ciudadanos de Quito. Dicha resistencia fue convocada por los poderes locales de esta ciudad, los que llamaron a cercarla y avisaron que buses, camiones, tractores y todo el transporte público serían utilizados para cortar los accesos a Quito.

Este hecho se percibiría como la "invasión costeña" de Quito (Ramírez, 2005: pp. 61-62). Y detonará un "malestar ético" y un "intenso sentimiento de injusticia” entre la población quiteńa contra el gobierno de Gutiérrez, exacerbado en los días de abril por lo que calificaron de actos de provocación y desafíos a la ciudad y al pueblo de Quito por parte del gobierno. Así se entendía el retorno de Bucaram, el decreto del estado de emergencia y la "invasión de las huestes gutierristas". Fue por eso que se activó

un maniqueo discurso de afirmación identitaria de la "quiteñidad" que recuperó la memoria del pasado rebelde y libertario de la ciudad —asociado con las primeras luchas independentistas y luchas anticoloniales que allí tuvieron su origen- y puso por delante la ficticia imagen de una ciudadanía (por esencia) digna, insurrecta, civilizada y democrática. La celebración de la identidad local fue, es, el desenlace lógico de la recomposición de un imaginario combativo y una representación virtuosa - de peligrosas consecuencias para las conflictivas dinámicas regionales del país - del pueblo de Quito luego de la caída del régimen (Ramírez, 2005: p. 72).

Por otra parte, múltiples sectores afines a Gutiérrez descalificaron la protesta por ser quiteño-céntrica; la Sierra, Quito, les había quitado a su presidente. Esta regionalización de la protesta serviría de excusa para que el gobierno de Palacio no tomara tan en cuenta la "agenda quiteña" (Ramírez, 2005: p. 101).

Es así que cuando RC decide salir del gobierno en septiembre de 2005, tiene la "novedosa" tarea de refundar las instituciones para lograr que verdaderamente funcionen como órganos de representación de los intereses del pueblo ecuatoriano, y la encomienda de "refundar, reconstruir la nación"; en suma, integrar a la población que seguía sin estarlo (indígenas, afroecuatoriano/fractura étnica) 
y limar la histórica fractura regional que dificulta la construcción de políticas públicas más allá de la regionalidad. Ese reto lo explicita RC (2004):

Construir verdaderos proyectos nacionales, incluyentes y en función del país, y que no reflejen simplemente las experiencias, percepciones, intereses y hasta novelerías de países y grupos dominantes. El primer paso de ese desafío es, como nos lo demuestran las contradicciones e incluso la doble moral de las políticas y reformas de los últimos ańos, más que mercados libres, crear un Estado verdaderamente libre de los atavismos y grupos de poder que lo dominan.

\section{La construcción de un contorno social como salida a la CEG: "Para volver a tener Patria"}

Siguiendo a Alba (2003: p. 55), "contorno social" se refiere a la articulación de elementos emergentes en una sociedad en proceso de desestructuración, como un esfuerzo por recuperar la estructuralidad. Esa articulación será posible en tanto exista un significante que la permita; surge cuando aparece un significante capaz de concentrar las particularidades de los elementos desarticulados y así formar una cadena equivalencial. La conformación de estos contornos sería un estado avanzado de la CEG.

Claramente se observa que la lógica de conformación del contorno social es similar a la lógica de la construcción hegemónica de Laclau (2005). No obstante, tomamos esta denominación porque Alba (2003) señala que los contornos sociales "se constituyen como espacios de significación articulados de manera inicial e incipiente", lo que nos hace tomarlos como antesala de la construcción de hegemonía en una situación de CEG. ${ }^{21}$ Es un proceso en el que los elementos de ruptura predominan frente a los de construcción o cierre de sentido de formación de una cadena equivalencial, por lo que es teóricamente conveniente dar a tal proceso una denominación diferenciada.

El contorno social se materializa en un estado de desestructuración en el que surgen nuevos procesos y fenómenos sociales que se muestran o como elementos que contribuyen a la desestructuración o como nuevos y, en muchos casos, momentos de incipientes condensaciones de significación con diversos grados de sedimentación, tendientes a conformar las nuevas estructuralidades

21 Laclau también ubica un escenario de crisis, una demarcación de la dicotomía del espacio social como antesala de la construcción hegemónica, pero con el objetivo de pensar la construcción de la hegemonía populista. Es por ello que aquí se retoma a Alba, ella no pretende ubicar como populista a la construcción hegemónica de RC, sino problematizar el contexto en el que su propuesta tiene lugar. 
sociales (Alba, 2003: pp. 52-53). Es decir, en este trabajo se analiza no tanto la construcción de una identidad hegemónica, sino el momento incipiente de construcción identitaria en un contexto de CEG, en el que para lograr su éxito primero debe incidir en la desestructuración, ya que es por esta que logra conformarse como hegemónica, o en términos electorales ecuatorianos, conseguir la mitad más uno de los votos. ${ }^{22}$

\section{El contorno social de RC: "Para volver a tener Patria"}

Retomaremos aquí dos características claves del contexto para el análisis de la formación del contorno social de RC.

1. Imposibilidad de solucionar la crisis por las tradicionales vías institucionales: evidente en el rechazo a todas las formas de representación de los intereses ciudadanos de la "revolución de Abril".

La revolución se dio, sin dudas, en medio de una situación de extrema emergencia. No sólo que se había sobrepasado el límite en la degradación del Estado de derecho, más allá del cual solo restaba la definitiva supresión de los derechos ciudadanos y/o el sostenimiento del régimen por la pura fuerza, sino que además los canales institucionales de resolución de la crisis estaban del todo sellados, anulándose unos a otros, y la insistencia en su viabilidad únicamente hubiese exacerbado la dinámica de confrontación desleal entre los actores políticos y carcomido, más aún, las estrechas bases de reconocimiento de cualquier instancia de regulación institucional de la política (Ramírez, 2005: p. 90).

2. Ausencia de gobierno hegemónico en el periodo que este artículo ha señalado para la CEG de Ecuador, esto es, 1998-2005, lo que describe Ramírez de la siguiente forma:

Las fracturas (regionales, económicas, sociales) entre grupos económicos y al interior de la clase política, y la intensa conflictividad social entre bloques de poder han contribuido a la escasa institucionalización del Estado de derecho y de los marcos normativos de la democracia y han profundizado la debilidad del Estado para coordinar, bajo mínimos consensos políticos, políticas nacionales incluyentes [...]

22 La ley electoral ecuatoriana para las elecciones de 2006 determinaba como necesaria la mayoría absoluta en primera o segunda vuelta. 
Esta fase puede caracterizarse entonces (la de la implementación de la agenda neoliberal) como un largo período de transición y ausencia de hegemonía política. [...] La precariedad constitucional, la imposibilidad de construir instituciones públicas duraderas, la deficiente gestión y capacidad distributiva de los diversos gobiernos y el consecuente repliegue de las élites tradicionales, y de los sectores emergentes, hacia el control de los feudos locales, hacen del estado una débil estructura política desde la cual construir campos hegemónicos y líneas consensuadas de ejercicio político (Ramírez, 2005: p. 93).

Es un contexto en el que la estructura institucional del Estado está imposibilitada para construir un proyecto hegemónico con el que se identifique la mayor parte de los ecuatorianos y, en particular, los que habían identificado con el “QQue se vayan todos!”.

Es un escenario donde el binomio Estado-nación ecuatoriano ya no funge como aglutinador de la comunidad. Por ello el lema de campaña "Para volver a tener Patria" de RC cumple con un objetivo primordial del Ecuador de ese momento: resignificar el significante Amo "Estado-nación-ecuatoriano". Es más, es de los pocos que lo podían hacer, en referencia a su contenido refundacional y abstracto (posibilidad de funcionar como significante flotante/Amo que signifique la cadena equivalencial/significante). Es con ese lema que RC resignificará las dos partes del binomio Estado-nación, en los términos que enseguida se analizan en este artículo.

\section{Formas de resignificar los significantes flotantes disponibles}

En una CEG hay tres formas ${ }^{23}$ de resignificar los elementos flotantes ${ }^{24}$ disponibles tras la desestructuración del sistema significante hegemónico:

1. Rasgos disruptivos: aparecen cuando determinados elementos inéditos o de formaciones sociales anteriores son significativos en el espacio social y cumplen con alguna de las siguientes funciones:

- Contribuir a la desestructuración de un orden en una coyuntura de CEG.

23 Un elemento puede ser nuevo, inédito y rasgo disruptivo, simultáneamente; esto es, que un significante eventualmente contiene dos o incluso tres características de los elementos flotantes, al tiempo que va cambiando la diferencia significante en el contexto de la crisis (Alba, 2003: p. 54).

24 Alba (2003) utiliza "elemento flotante" como sinónimo del "elemento" con el que Laclau conceptualiza a los significantes que no están articulados, es decir, a toda diferencia que no se articula discursivamente. 
- Aparecen de forma disruptiva, pero tienden a conformar los contornos de una nueva configuración social discursiva.

2. Elementos provenientes de las estructuras que se encuentran en desestructuración, de cierta forma excluidos de las mismas y que aparecen en el proceso de la CEG reactivamente.

3. Elementos inéditos que aparecen, se constituyen y expresan en el contexto de la CEG.

En nuestro caso de estudio se han detectado elementos de las tres características, los cuales exponemos abajo indicando el tipo de elemento que contiene el sentido relevante para este trabajo, esto es, marcando la forma en la que se articula en la "nueva" cadena equivalencial que culmina en la resignificación del significante Amo Estado-nación ecuatoriano, así como incluyendo párrafos de los dos textos objetos de análisis a modo de ejemplo.

1. Elementos disruptivos.

A/ El "apartidismo".

La postulación de RC como outsider y sin ningún candidato para el Congreso se basa en la estrategia de ahondar en la deslegitimación de la clase política para presentarse como el único candidato que no pertenece a la misma y, por esto, ser el único libre de culpa. Los continuos ataques a la "partidocracia", su señalamiento explícito de los grandes culpables de la situación ecuatoriana son parte clave de su estrategia, ya que de la desestructuración del sistema RC obtiene una buena parte de su fortaleza.

En consecuencia, este elemento es disruptivo debido a que ahonda en la crisis política y de representación, con lo que contribuye a la desestructuración del orden en una coyuntura de CEG.

— Todo este recetario de políticas obedeció al llamado "Consenso de Washington”, supuesto consenso en el que, para vergüenza de América Latina, ni siquiera participamos los latinoamericanos. Sin embargo, dichas "políticas" no fueron solo impuestas, sino también agenciosamente aplaudidas, sin reflexión alguna, por nuestras élites y tecnocracias.

- Hoy, ya no tenemos moneda nacional, no está más la simbología heroica del Mariscal de Ayacucho, pero los culpables de esta destrucción, la banca y el Banco Central, están más prósperos que nunca.

- El Congreso Nacional, supuestamente máxima expresión de la democracia representativa, no es percibido por la ciudadanía como su representante.

Discurso de investidura. 
RC profundiza en la desestructuración del sistema y propone una nueva estructuralización con su candidatura. Incidiría así en la deslegitimación del "Estado" actual en aquel entonces, vía la crítica de los que ejercían el poder, para resignificar esa parte del binomio con su propuesta de Revolución Ciudadana. ${ }^{25}$ Este hecho, sumado a su postulación como candidato para gobernar uno de los poderes del sistema democrático, así como la promesa de conformar una Asamblea Constitucional que reconstituyera el sistema, poseen la doble función de desestructurar y estructurar.

El primer eje de esa revolución ciudadana es la revolución constitucional. El mandato de la ciudadanía fue claro: queremos una transformación profunda, nuestras clases dirigentes han fracasado, queremos una democracia donde se oiga nuestra voz, donde nuestros representantes entiendan que son nuestros mandatarios, y que los ciudadanos somos sus mandantes.

Discurso de investidura.

En este punto vemos como RC, al igual que la revolución de Abril, son fuertemente institucionales, pero para conseguir su propósito deben primero ahondar en la desestructuración de las instituciones anteriores.

2. Elementos excluidos de las estructuras en proceso de desestructuración y que aparecen de forma reactiva en el proceso de CEG.

A/ "Para volver a tener Patria".

El lema "Para volver a tener Patria" cumple una doble función. Resignifica la nación al anunciar que no se tenía patria y, por tanto, propone cómo tenerla; y también resignifica al Estado al señalarlo como culpable de tener que realizar esta labor, pues ha "vendido la patria".

Ecuador es un país que históricamente ha vivido diferentes llamados a "reconstruir-rehacer" la nación, antes del enunciado en 2006 por RC, el último lo había emitido el político e intelectual Benjamín Carrión ${ }^{26}$ (de quien RC parafrasea el lema) tras la derrota de Ecuador frente a Perú a comienzos de la década de los cuarenta.

25 Los ejes programáticos desarrollados en su discurso de investidura y en el Plan de Gobierno Plurianual son: i) Revolución constitucional y democrática, ii) Revolución ética: combate frontal a la corrupción, iii) Revolución económica y productiva, iv) Revolución educativa y de salud, y $v$ ) Revolución por la dignidad, la soberanía y la integración latinoamericana.

26 Benjamín Carrión propuso en Cartas al Ecuador la patriótica tarea de devolverle al país la autoestima tras perder la guerra y parte del territorio contra Perú, para eso acuńó la célebre frase "para volver a tener Patria”. Carrión detectó un estado de desengańo en el Ecuador frente al cual era necesario devolver la esperanza a los ciudadanos de que el futuro podía ser mejor. 
Para muchos volver a construir patria en 2006 fue una "sorpresa", más aún porque al haberse declarado Ecuador constitucionalmente en 1998 como "unitario, pluricultural y multiétnico", se pensaba que ya se había conformado una nación incluyente (Zepeda, 2010: p. 163), es decir, con indígenas y afrodescendientes en igualdad de oportunidades.

Hace ya más de 50 años, cuando nuestro país estaba devastado por la guerra y el caos, el gran Benjamín Carrión expresaba la necesidad de volver a tener Patria. Esta frase fue la inspiración de un puñado de ciudadanos que decidimos liberarnos de los grupos que han mantenido secuestrada a la Patria, y así emprender la lucha por una revolución ciudadana, consistente en el cambio radical, profundo y rápido del sistema político, económico y social vigente, sistema perverso que ha destruido nuestra democracia, nuestra economía y nuestra sociedad.

Discurso de investidura.

Pero RC no solo advierte la necesidad de tener patria por medio de la inclusión de la población históricamente discriminada, sino que pone en juego la idea de una necesaria segunda independencia tanto al interior del país como respecto del exterior. Es decir, Ecuador se independiza de Espańa en el siglo xIx bajo el liderazgo de Simón Bolívar y a principios de siglo xx de las fuerzas reaccionarias del país, opuestas al progreso, y de la injusticia social de la mano del Viejo Luchador, José Eloy Alfaro. Esta doble independencia es la que manifiesta $\mathrm{RC}$ en sus discursos; no solo se requiere una soberanía ante los poderes extranjeros, sino que se debe evitar que los poderes internos "vendan el país".

Y fue 100 años después de la gesta libertaria bolivariana que volvió a despertar el pueblo, liderado por el general Eloy Alfaro — discípulo de Montalvo y amigo de Martí-, para quien "en la demora estaba el peligro". Ahora, a los cien años de la última presidencia de Alfaro, nuevamente ese despertar es incontenible y contagioso. Solamente ayer, en el páramo de Zumbahua, con nuestros hermanos indígenas, se repetía aquel coral rebelde y cívico que inunda las calles de América: "Alerta, alerta, alerta que camina la espada de Bolívar por América Latina”.

Discurso de investidura.

B/ "La Patria no se vende".

Situaremos en este rubro la resignificación del "Estado" en referencia a la forma de gobernar "hacia fuera" y "vender el país" de la clase política ecuatoriana. El discurso de RC enfatiza en la escasa calidad democrática y culpabiliza a una 
parte de la sociedad, a los pelucones, ${ }^{27}$ de usar el poder sistemáticamente en su beneficio y en contra de la mayoría. RC evidencia que la sociedad ecuatoriana es desigual e injusta desde tiempos de la colonia, y que los responsables de esto siguen siendo los mismos.

Hasta ahora los sueńos de los pueblos del Ecuador se han visto truncados por los sucesivos desgobiernos, por la partidocracia, por la oligarquía y su búsqueda desmesurada de rentas, y también por las imposiciones foráneas. Todos ellos nos han conducido a tocar fondo, nos han llevado a sumirnos en las peores condiciones de pobreza, de desigualdad, de descomposición social y de deterioro ambiental. Pero lo que no han podido hacer es quitarnos la capacidad de soñar, para hacer de nuestros sueños un ejercicio colectivo de liberación y cambio radical. Pero también hay que reconocer que como sociedad nos ha faltado la coherencia histórica y la unidad política; "divide y vencerás" ha sido la estrategia de los grupos dominantes, que tienen al país en estas deplorables condiciones.

Plan Plurianual (PP), p. 6.

Las propuestas iniciales de RC fueron técnicas, con mucho contenido específico rechazando la firma del TLC y declarando la caducidad del contrato con la estadounidense oxy (Occidental Petroleum Corporation). Era un nacionalismo vinculado a la soberanía en materia económica, sobre todo para que esta representara los intereses del país y no los de los "mercados" (Recalde, 2006: p. 20). Por eso el título de su discurso de investidura, "Más que liberar mercados hay que liberar el país", evidencia que la fuerte carga de resignificar la "Nación", va de la mano de la parte que al Estado como gobernante le es propia.

27 El término pelucones denominaba a la aristocracia y a la burguesía criolla que se formó tras la independencia de España y se potenció con el gobierno conservador de Juan José Flores; estos burgueses no necesariamente tenían linaje. RC usó esa palabra para etiquetar a la parte de la sociedad ecuatoriana que solo miraba por sus intereses y no por los nacionales. El término pelucones también tiene historia en Chile y Perú (chapetones). En Chile, denominó en la primera mitad del siglo xix a los conservadores o realistas que mantenían vínculos de dependencia con el imperio espańol. Desde una perspectiva económica y siguiendo a Acemoglu \& Robinson (2012) es posible decir que esta clase sería la de las "élites extractivas": aquellas que se apartan del bien común y dedican sus esfuerzos a su propio bienestar y al del grupo al que pertenecen desde el mundo de las finanzas, la economía, la política, los medios de comunicación o la inteligencia. Ellos conforman las instituciones extractivas que concentran el poder en una élite reducida a la que fijan pocos límites en el ejercicio de aquel. De igual modo, dichas élites construyen un sistema de captura de rentas que les permite, sin crear riqueza, detraer rentas de la mayor parte de la ciudadanía en beneficio propio. 
No negociaré con nadie la dignidad de la Patria. La Patria ya no está en venta. El oprobio del pasado histórico, con la venta de la bandera o pactos que canjeaban votos por prebendas, ha terminado para siempre.

Discurso de investidura.

Ambos elementos son vitales en campaña y los dos adquieren peso según el momento en el que se encuentran. Es un manejo que RC explica de la siguiente forma:

Nuestra lucha era contra el establishment politico. Si cambió el escenario que esperábamos. Nosotros pensábamos pasar a la segunda vuelta con León Roldós, ahi se hubiera podido continuar con el mensaje de la ciudadanía contra la partidocracia, pero pasamos con Álvaro Noboa. Hay que hablar de seguir teniendo patria o tener un (Anastasio) Somoza (El Universo, 16 de septiembre de $2006^{28}$ ).

3. Elementos inéditos.

Como elementos inéditos que resignifican al unísono las dos partes del significante Estado-nación discutiremos: i) la inclusión de la mujer y la centralidad de su discriminación como un problema de Estado, ii) el dejar de apelar a la ciudadanía de forma paternalista para hacerla corresponsable del proyecto y de la crisis, y iii) la cosmovisión indígena del "sumak kawsay" o "buen vivir" como filosofía del país que se propuso para sustituir a la neoliberal, acción que así incluía lo "indígena” en la esencia de la nación, ya no como lastre, postulándolo como fuerza nacional y no regional.

i) La cuestión de género.

En referencia a la mujer, Zepeda (2010: 182) afirma que lo novedoso es que "las mujeres pasan a formar parte de la patria a través de su investidura como próceres”. Manuela Sáenz, compañera fuera del matrimonio de Simón Bolívar y por ello no muy bien tratada por la historia, es convertida en "Generala de la República de Ecuador". Dolores Cacuango, quien en 1946 funda la Federación Ecuatoriana de Indios e impulsa las escuelas bilingües espańol/quechua, junto con Tránsito Amaguaña, quien también luchara por implantar un sistema cooperativista en el campo, son mujeres indígenas también revaloradas.

Este primer programa presentado ahora como gobierno, ha sido elaborado concertada y participativamente por hombres y mujeres; pero esta construcción no se

28 Recuperado de http://www.eluniverso.com/2006/11/16/0001/8/124F34C470FA43B8ADDCBF977 B9810DD.html, consultado el 23 de marzo de 2015. 
agota aquí, ni se han abordado todos los temas; recién empieza, tenemos mucho más que proponer. Para ello, invitamos a seguir soñando con los ideales y pensamientos de nuestras Manuelas —Espejo, Cañizares y Sáenz_-, incansables en su apoyo a los procesos libertarios de nuestro país y celosas defensoras de la dignidad de nuestro pueblo. Nos alimentamos de las ideas y coraje de Dolores Cacuango y de Tránsito Amaguańa, valerosas dirigentes indígenas que han entregado su vida por la libertad y los derechos de los pueblos indígenas. [...] Para enfrentar las profundas inequidades de género, así como la discriminación y violencia cotidiana contra la mujer, proponemos rupturas y alternativas posibles, gestadas en un diálogo constructivo entre mujeres y hombres en todos los ámbitos de la sociedad, tanto en el espacio público (organizaciones sociales y políticas), como en el privado.

Plan Plurianual (PP), p. 11.

La cuestión de género se tratará en estrecho vínculo con el resto de grupos discriminados tradicionalmente, agregando a la fractura étnica un "nuevo" componente, el género, que normalmente agudiza esa discriminación.

De igual manera lucharemos contra la discriminación en todas sus formas, sobre todo la de género y étnica. Aunque todavía nos falta mucho por hacer, ya hemos dado los primeros pasos al contar por primera vez en la historia con un gabinete donde más del 40 por ciento de sus miembros son mujeres, así como al tener el primer ministro afroecuatoriano de la historia del país, nuestro entrańable poeta Antonio Preciado.

Discurso de investidura.

La consideración fundamental para construir el nuevo país es incorporar a toda la población en la definición de su presente y de su futuro. No aceptamos que sea sólo una fracción de la sociedad la que organiza la vida nacional. Esto significa garantizar el acceso adecuado a todos los habitantes del país en la toma de las decisiones, y eso pasa por el logro de un nivel de bienestar que responda a sus necesidades mínimas básicas, a su interés de desarrollo. Eso exige su conversión en ciudadanos y ciudadanas.

Plan Plurianual (PP), p. 5.

ii) La inclusión no pasiva-paternalista de la ciudadanía: La Revolución Ciudadana.

Desde que no se postuló como parte de la "partidocracia", RC hizo una arriesgada apuesta para conseguir la adhesión ciudadana. Como ya explicamos, en el contexto del Ecuador de aquel momento, proponerse como representante de los sin representante, como un outsider o un ciudadano más, era la única 
posibilidad de llegar al gobierno. No obstante, esto no implica que se quiera contar con el pueblo para gobernar o que se le considere capacitado para hacerlo. Mucho menos que se le adjudique parte de culpa en la marcha del país. En el discurso de RC él ejerce de líder, pero hay una directa apelación a la necesidad de que el pueblo ecuatoriano se implique en el cambio para que el proyecto no sea un fracaso. La Revolución Ciudadana liderada por Rafael Correa será posible si es verdaderamente ciudadana.

Para cristalizar este sueńo colectivo no partimos de cero. La construcción de un nuevo país no implica crear un nuevo régimen de dominación. Es una tarea para ampliar las libertades a partir de cada vez más igualdad en todos los órdenes de la vida. Esta no es una tarea de "expertos", es materia de discusión y decisión de la sociedad en su conjunto y de personas concretas involucradas en este proceso de cambio. La gente no será beneficiaria pasiva de este esfuerzo, la gente será la portadora activa de su propia emancipación.

Plan Plurianual (PP), p. 8.

De igual forma, RC señalará en su discurso de investidura, aunque sesgadamente, la corresponsabilidad de la sociedad frente a la situación que el país vivía, en el sentido de que la "avaricia" del modelo neoliberal estaba profundamente enraizado en ella, al igual que la corrupción.

El segundo eje de la Revolución Ciudadana es la lucha contra la corrupción, mal enraizado en nuestra sociedad, pero también exacerbado por modelos, políticas y doctrinas que ensalzaron el egoísmo, la competencia y la avaricia como el motor del desarrollo social. Estas aberraciones también tuvieron fuertes efectos en la seguridad ciudadana y en los niveles de violencia, no solo por la inequidad y pauperización que las políticas aplicadas en los últimos ańos han generado, sino también porque si la competencia es buena en lo económico, ¿por qué no también competir en las calles?

Discurso de investidura.

[...] también hay que reconocer que como sociedad nos ha faltado la coherencia histórica y la unidad política; "divide y vencerás" ha sido la estrategia de los grupos dominantes, que tienen al país en estas deplorables condiciones.

Plan Plurianual (PP), p. 6.

Por tales causas fue que propuso otro modo de vida que rompía con las filosofías occidentales y adoptaba la cosmovisión indígena. 


\section{El concepto de sumak kawsay o buen vivir.}

La propuesta gubernamental del sumak kawsay o buen vivir, ${ }^{29}$ como filosofía de país que conducirá al cambio, no solo lo interpretaremos como una propuesta de forma de vida en sustitución del neoliberalismo, sino también como una forma no idílica de incluir en el discurso de $\mathrm{RC}$ a la población indígena como parte central de la ecuatorianidad, es decir, prescindiendo del glorioso pasado indígena pero apelando a lo que sus formas de convivencia pueden aportar a la nación, en particular en lo referente a la común (organización, justicia, convivencia) y a su cosmovisión (relación con el territorio, gestión y explotación de recursos naturales) en la actualidad.

[...] consideramos crucial ejercer el principio de la diversidad cultural teniendo en cuenta la continuidad histórica de los pueblos originarios, actores fundamentales de la vida nacional, y que se han constituido, especialmente en las dos últimas décadas, a través del movimiento indígena, en defensores de la democracia. Esto nos conduce a cuestionar desde sus raíces el actual modelo de desarrollo: excluyente, marginador, inequitativo, racista, depredador de la economía, la sociedad y la naturaleza.

Plan Plurianual (PP), p. 6.

En cuanto al carácter regional, $\mathrm{RC}$ se postuló desde el principio como un líder nacional, haciendo hincapié en que los problemas importantes eran de índole nacional (modelo económico, corrupción, etc.). Esta posición, como ya se dijo arriba, es muy arriesgada en un país donde el no inclinarse por una parte del país se considera como traición de los intereses regionales. No obstante, el contexto de CEG permitió que RC se postulara de esa forma, ya que había un serio daño debido a la ilegitimidad de los tradicionales representantes de los intereses regionales.

29 El "sumak kawsay" o "buen vivir" no aparece en los dos textos objeto de análisis, pero forma parte de la propuesta de RC como lo comprueba su presencia en la Constitución ecuatoriana de 2008. El sumak kawsay es una concepción de vida de la región andina, en la cual la participación de los seres humanos se visualiza como un conjunto vital de carácter cósmico, en estrecha relacionalidad o armonía con la naturaleza. La Constitución ecuatoriana lo retoma y propone como objetivo de vida en sociedad, como una "convivencia ciudadana en diversidad y armonía con la naturaleza". En la nueva Constitución es un concepto holístico que fundamenta e integra todos los aspectos de la vida política (Cortez, 2010: p. 227), lo cual se recoge en el art. 275: "El régimen de desarrollo es el conjunto organizado, sostenible y dinámico de los sistemas económicos, políticos, socio-culturales y ambientales, que garantizan la realización del buen vivir, del sumak kawsay [...] El buen vivir requerirá que las personas, comunidades, pueblos y nacionalidades gocen efectivamente de sus derechos, y ejerzan responsabilidades en el marco de la interculturalidad, del respeto a sus diversidades, y de la convivencia armónica con la naturaleza." 
Sońamos en un país con un sistema político capaz de solucionar los conflictos en función de los intereses nacionales. Soñamos en un país con un sistema económico y social con capacidad de emprender retos verdaderamente nacionales y de larga duración. Sońamos en un país con un Estado solidario, moderno, cuya gestión pública sea eficiente, eficaz y descentralizada, que responda a las demandas de un proceso de desarrollo equilibrado de las regiones, que fortalezca la democracia, que coadyuve con la transparencia de dicha gestión, y que, sobre todo, propenda a fortalecer el carácter nacional del Estado.

Plan Plurianual (PP), p. 7.

\section{Conclusión}

Hemos analizado la propuesta de RC como enfocada en devolver la confianza en las instituciones del Estado, en un contexto de CEG que había resultado de dos décadas en las que la consigna era la retirada o estrechamiento del Estado. El objetivo ha sido estudiar esa propuesta como ejemplo de lo sucedido en el Cono Sur entre finales del siglo xx e inicios del xxI, cuando nuevos liderazgos protagonizaron el "giro a la izquierda", como respuesta sintomática a la desestructuralización que vivía una buena parte de la región.

Hemos visto cómo RC subraya las contradicciones entre la incapacidad institucional, la pasividad de una parte de la sociedad y las protestas de esta durante las últimas décadas, en particular la "revuelta forajida", para mostrar el deterioro institucional que exigía su refundación. Es decir, que RC llevó al extremo el descrédito del sistema, y proponía que él y su proyecto político eran la única salida a la crisis.

Este ejercicio de descrédito de la clase dirigente valdría para RC — al igual que a otros gobiernos de la región como Venezuela, Bolivia y Argentina- el denostado calificativo de "populista", pues se asumía que proponer al unísono una revolución y su institucionalización mediante un fuerte liderazgo violentaba el sistema democrático. No obstante, aquí hemos querido mostrar cómo, para salir de la CEG, era necesario que Ecuador resignificara el significante Estadonación comprendiendo tanto a lo externo o contextual -léase las políticas neoliberales y su aplicación en el país_-, como a lo interno o histórico, en relación con las fracturas étnica y regional, más un tercer componente: la fractura de clase, que señalaba la culpa de las tradicionales élites políticas y económicas en la marcha del país.

En conclusión, entre lo más importante aquí recogido, se debe decir que la llegada de RC al poder mediante una radicalización (outsider, Asamblea Constituyente, desafíos a los organismos de crédito internacional, presentándose 
como opción nacional) no se hubiera dado sin la CEG que vivía Ecuador y si este país no hubiera estado en un momento en el que era primordial devolver la confianza y legitimidad al Estado que gobierna a la Nación, tras dos décadas en las que aquel se había manejado por los intereses de las organismos internacionales de crédito en connivencia con las élites locales.

RC definiría dicha situación al final de su discurso de investidura de la siguiente forma: "Felizmente, como decía el general Eloy Alfaro, la hora más oscura es la más próxima a la aurora, y el nefasto ciclo neoliberal ha sido definitivamente superado por los pueblos de Nuestra América, como lo demuestran los procesos de Argentina, Brasil, Uruguay, Venezuela, Bolivia, Chile, Nicaragua y ahora Ecuador".

Con dicho discurso, programa de gobierno y acción política, $\mathrm{RC}$ ha sido reelecto en dos ocasiones, 2009 y 2013, por más del 50\% del electorado ecuatoriano.

\section{Referencias}

\section{Bibliohemerografía}

Acemoglo, D. \& Robinson, J. (2012). Por qué fracasan los paises. Barcelona: Deusto.

Alba, A. del. (2003). Crisis estructural generalizada: sus elementos y sus contornos sociales. En Alba, A. del (Ed.). Filosofia y teoría en el campo de la educación: perspectivas nacionales y regionales. México: Consejo Mexicano de Investigación Educativa, A. C.

Alcántara, M. \& Freidenberg, F. (2001). Cuestión regional y política en Ecuador: Partidos de vocación nacional y apoyo regional. América Latina Hoy, 27, 123-152.

Badiou, A. (1988). Leêtre et l'événement. París: Seuil.

Barrera, A. (2008). Dinámicas sociopolíticas en la construcción de Alianza PAIs. En Ramírez, F. (Ed.). La innovación partidista de las izquierdas en América Latina. Quito: ILDIS/FES.

Correa, R. (2004). De Banana Republic a la No República: Las Tres Últimas Décadas de la Historia Económica del Ecuador. Quito: Universidad "San Francisco de Quito”. Documento de Trabajo.

Cortez, D. (2010). Genealogía del "buen vivir" en la nueva Constitución ecuatoriana. En Fornet-Betancourt, R. (Ed.). Gutes Leben alsgmailggma humanisiertes Leben. Vorstellungen vom guten Leben in den Kulturen und ihre Bedeutung für Politik und Gesellschaft heute. 
Dokumentation des VIII. Internationalen Kongresses für Interkulturelle Philosophie. Denktraditionen im Dialog. Studien zur Befreung und Interkulturalität. Band 30. Wissenschaftsverlag Main.

Derrida, J. (1994, 12 de octubre). A democracia é uma promessa. Jornal de Letras e Ideias. Recuperado de http://www.infoamerica.org/documentos_pdf/derrida02.pdf

Echeverría, J. (2010). Complejización del campo político en la construcción democrática del Ecuador. En Burbano, F. (Ed.). Transiciones y rupturas. El Ecuador en la segunda mitad del siglo XX. Quito: Flacso Ecuador.

Laclau, E. (2008, 12 deabril). "Los desafíos del populismo en América Latina”. Charla en Morón. Recuperado de www.nuevomoron.org.ar/interiores/noticias/graficos/12_04_08/ErnestoLaclau.pdf

Muteba Rahier, J. (1999, enero). Mami, ¿qué será lo que quiere el negro? Representaciones de gente negra en la revista Vistazo 1957-1991. Iconos. Revista de Ciencias Sociales, 7, 96-105.

Plaza, D. \& Larrauri, G. (2010, Primavera). El fútbol y la construcción de una representación social llamada nación. Versión, 24, 227-248.

Ramírez Gallegos, F. \& Taller El Colectivo. (2005). La insurrección de Abril no fue solo una fiesta. Quito: Abya-Yala.

Ramírez Gallegos, J. P. \& Ramírez Gallegos, F. (2005). La estampida migratoria ecuatoriana. Crisis, redes transnacionales y repertorios de acción migratoria. Quito: Centro de Investigaciones de la Ciudad. Recuperado de http://bibliotecavirtual.clacso.org.ar/ar/libros/ecuador/ ciudad/ramirez.pdf

Recalde, P. (2007, enero). Elecciones presidenciales 2006: una aproximación a los actores del proceso. Iconos. Revista de Ciencias Sociales, 27, 15-25.

Walsh, C. \& García, J. (2002). El pensar del emergente movimiento afroecuatoriano: Reflexiones (des)de un proceso. En Mato, D. (Ed.). Estudios y otras prácticas intelectuales latinoamericanas en cultura y poder. Caracas: CLACSO/CEAP/FACES/Universidad Central de Venezuela.

Zepeda, B. (2010). Construyendo la nación en el siglo xxi: la "Patria" en el discurso de Rafael Correa. En Burbano, F. (Ed.). Transiciones y rupturas. El Ecuador en la segunda mitad del siglo $X X$. Quito: Flacso Ecuador. 


\section{Documentos oficiales}

Constitución de la República del Ecuador. (2008). Ciudad Alfaro: Asamblea Constituyente.

OEA. (2008). Informe de la misión de observación electoral de la OEA en la república del Ecuador [Elecciones generales del 15 de octubre de 2006 y presidenciales (segunda vuelta) del 26 de noviembre de 2006]. Washington, D. C.: OEA.

SEnplades. (2007). Plan Plurianual del Gobierno del Presidente Constitucional de la República de Ecuador Economista Rafael Correa. Quito: SENPLAdEs.

Correa, R. (2007). Discurso del presidente de Ecuador. "MÁs QUe LIBERAR MERCADOs, HAY QUE Liberar al país”. Pronunciado en la toma de posesión de la Presidencia de la República el 15 de enero de 2007. En Tareas. Panamá: Cela, Centro de Estudios Latinoamericanos Justo Arosemena.

Recibido el 13 de septiembre de 2014. Aceptado el 16 de junio de 2015. 